\title{
Filtering Facepiece Respirator Supply Chain Management Framework in a Disaster Such as COVID-19
}

\author{
Kihyung Kim ${ }^{1, *(D)}$ and Li Zhao ${ }^{2}$ \\ 1 Trulaske College of Business, University of Missouri, Columbia, MO 65211, USA \\ 2 Textile and Apparel Management, University of Missouri, Columbia, MO 65211, USA; Zhaol1@missouri.edu \\ * Correspondence: kimkihy@missouri.edu
}

check for updates

Citation: Kim, K.; Zhao, L. Filtering Facepiece Respirator Supply Chain Management Framework in a Disaster Such as COVID-19. Societies 2021, 11, 136. https://doi.org/ $10.3390 /$ soc 11040136

Academic Editors: Sandro Serpa and Carlos Miguel Ferreira

Received: 12 August 2021

Accepted: 8 November 2021

Published: 11 November 2021

Publisher's Note: MDPI stays neutral with regard to jurisdictional claims in published maps and institutional affiliations.

Copyright: (c) 2021 by the authors. Licensee MDPI, Basel, Switzerland. This article is an open access article distributed under the terms and conditions of the Creative Commons Attribution (CC BY) license (https:/ / creativecommons.org/licenses/by/ $4.0 /)$.

\begin{abstract}
Due to the lack of vaccines and treatments, filtering facepiece respirators are a primary and effective tool to dampen the spread of COVID-19. To meet the huge and continuous demand for filtering facepiece respirators, this concept paper suggests a supply chain management framework based on the disaster management principle. This concept paper adopts an exploratory and qualitative literature review to provide managerial insights for the supply chain participants. Due to implementation delay and strategic interdependency, the supply chain management strategies need to be systematically integrated. A viable way to integrate strategies is based on the disaster management cycle: mitigation, preparation, response, and recovery phases. Our model integrates innovative and successful but overlooked supply chain management strategies. First, the production capacity should be flexible so that the production mode in emergency and normal situations can be different. Second, the concept paper and development facilities can utilize their capacities for actual production in emergencies. Third, the quality certification process should accommodate the flexible production capacities. Fourth, inventory stockpiling should be renewable. This concept paper contributes to policymakers, healthcare sector decision-makers, stakeholders throughout the FFR supply chain to cope with future crises caused by pandemics by providing a systematic approach to constructing an effective, flexible, and resilient supply chain.
\end{abstract}

Keywords: COVID-19; filtering facepiece respirators; supply chain management; disaster management cycle

\section{Introduction}

In 2020, coronavirus disease 2019 (COVID-19) spread all over the world. To control the disease outbreak, it is essential for the public to wear filtering facepiece respirators (FFRs), such as surgical and N95 masks. Unfortunately, the capacity of the FFR supply chain is insufficient to fulfil the sudden and huge demand under this disastrous situation. To protect society from another respiratory disease pandemic, it is urgent for researchers, industry practitioners, and governments to construct effective FFR supply chains. To answer this urgent need, this concept paper provides an implementable framework that integrates supply chain management (SCM) strategies based on the crisis management principle through extensive case study reviews.

COVID-19 is caused by severe acute respiratory syndrome coronavirus 2 (SARS-CoV-2) that is highly contagious with human-to-human transmission. PPE, such as FFRs, medical gowns, gloves, and goggles, protect the wearers from the virus's transmission. We focused on FFRs because other PPE is mainly consumed by restricted users such as healthcare providers. This implies the demand for FFRs is much larger than that for other PPE, and this causes formidable challenges. In addition, we focused on disposable masks and respirators and excluded cloth masks. Cloth masks are made of a normal woven fabric and cover the wearer's mouth and nose. The effectiveness of cloth masks is questionable [1,2]. Moreover, supply shortages do not occur for cloth masks because people can make cloth masks using their own fabric. 
Due to the shortage of vaccines and lack of treatments, FFRs are a primary and effective tool to dampen the spread of COVID-19. Accumulated evidence supports the idea that "public mask wearing is most effective at stopping spread of the virus when compliance is high [3]." Moreover, when a mask can filter small sized airborne particles, it protects the wearer more effectively [1]. Recent observations and empirical studies show that COVID-19 transmission is lessened when the public wears FFRs. For example, the citizens of South Korea and China actively wear FFRs, and the countries have successfully controlled the spread of COVID-19 compared to other countries [4]. Chu et al. [1] found that "face mask use could result in a large reduction in risk of infection, with stronger associations with N95 or similar respirators compared with disposable surgical masks or similar."

The demand for FFRs has been huge and continuous during the pandemic. The global yearly market volume of FFRs was less than $\$ 356$ million dollars in 2018 [5]. According to the Ministry of Food and Drug Safety of South Korea (MFDS), the monthly FFR market size of South Korea in June 2020 was approximately $\$ 400$ million dollars. The demand for FFRs exploded during the pandemic such that a country's monthly market size exceeded the world's annual trading volume two years ago. The demand for FFRs is huge because both healthcare providers and all of society should wear FFRs to curb spread of the contagious disease. Moreover, the demand is continuous throughout the pandemic period because FFRs are designed to be disposable.

Unfortunately, the FFR supply did not meet the sudden and huge demand for FFRs in the early stage of the COVID-19 pandemic. Due to the supply shortages of personal protective equipment (PPE) including FFRs, many countries, including the most developed countries in the world such as the U.S. and the U.K., there was a failure to curb the spread of COVID-19 before it became a pandemic [5-7]. The failure has resulted in a disastrous loss of lives and enormous economic damage worldwide. Revisiting the supply chain of FFRs and finding solutions for future needs is very important.

To achieve our theoretical goals, we first reviewed extensive articles and case studies about the countries that successfully contained the COVID-19 outbreak. We then examined perspective articles that discuss similar strategies that we find in the case studies. We suggested a conceptual model to build an FFR supply chain that effectively copes with future emergencies. In particular, supply chain management framework and disaster management cycle were used to envision the FFR supply chain. The gap between the regular FFR supply chain capacity and the demand for FFRs during the initial stage of COVID-19 pandemic was examined. Four phases of disaster management cycle including mitigation, preparation, response, and recovery were discussed. Considering four pillars in the FFR supply chain including information, production, distribution, and sustainability, we demonstrate detailed strategies under each stage for an effective FFR supply chain. We assert that the systematic management of the entire supply chain is crucial. An anecdote illustrates the importance of taking a supply chain viewpoint. This study aims to propose solutions for future emergencies that the FFR supply chain may face.

\section{Literature Review}

We conducted an unstructured literature review, starting with industry news and reports related to FFR shortages in our supply chain. Journal articles were reviewed to formulate research problems and identify solutions. Articles were gathered from three areas: SCM, disaster management, and COVID-19 updates. Articles were selected using both inclusion and exclusion criteria. We included both qualitative and quantitative studies with keywords 'personal protective equipment', 'filtering face mask', 'supply chain', and 'COVID'. Non-English articles were excluded. We select relevant articles based on our experience. Then, we explored and selected theoretical studies to construct the framework of this study based on our experience as well.

We built a conceptual model based on the integration of SCM with the disaster management cycle. The SCM approach tracks the increasing value of FFR from raw 
material to the final product. The SCM approach has the advantage of identifying the extent of the gap between supply and demand at each stage of production. This advantage is important to account for the bottleneck in FFR production. However, bottlenecks vary from situation to situation. The SCM approach is limited in understanding the dynamics of bottlenecks. The disaster management framework provides a complementary perspective for addressing fluctuating bottlenecks in the FFR supply chain. Disaster management provides a procedural approach to responding to crises caused by a disaster, called the disaster management cycle. This article provides a constructive framework for addressing the crisis in the FFR supply chain caused by the COVID-19 disaster by integrating the SCM approach with the disaster management cycle approach.

\subsection{SCM Approach in Managing FFR Supply Chain Reacting to the COVID-19 Crisis}

There is a gap between the regular FFR supply chain capacity and the demand for FFRs during the COVID-19 pandemic. For instance, at the beginning of April 2020, the U.S. government ordered 3M, one of the major FFR producers in the world, to produce more masks based on the Defense Production Act. However, it was difficult for $3 \mathrm{M}$ to follow the order due to the insufficient nonwoven melt-blown filter (MB filter) supply [8]. Many reports agree with our perspective that coherent and systematic strategies are required throughout the FFR supply chain to cope with the disastrous situation [9-11]. The gap identifies the challenges to coping with the surging demand for FFRs during a respiratory contagious disease outbreak.

The supply chain starts with raw material suppliers and ends with the end users. Figure 1 depicts the core structure of the FFR supply chain. This paper focuses on the three main tiers (component providers, manufacturers, and distribution channels) and the quality certification process.

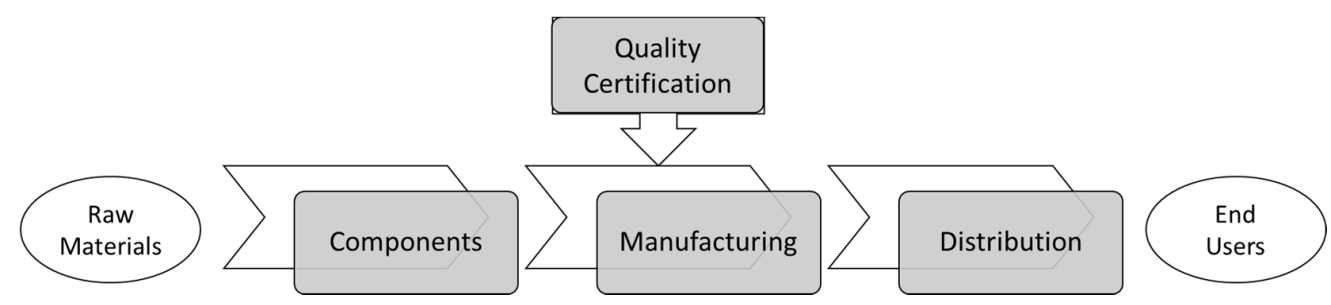

Figure 1. FFR supply chain.

The FFR components include MB filters, ear-loop or head-loop straps, and main bodies that are made up of plastic or fabric. Among the raw materials, the key component is the MB filters. The MB filter is produced through a nonwoven web-forming process known as melt blowing to form fine fiber [12]. FFRs filter out droplets and airborne particles that contain viruses by using this material as a filter. In 2019, the U.S. capacity of melt-blown fiber was estimated to be 250,000 metric tons per year and $34 \%$ of the fiber was used for filtration media [13]. One ton of MB fiber yields 1 million filters, and FFRs contain 1-4 filters, depending on their protection level.

The manufacturers assemble the components as FFRs. The FFR manufacturing capacity is highly concentrated in a couple of regional clusters. Notably, China possesses much of the capacity. The FFR manufacturing capacity is distributed over three major regional clusters: the U.S., Asia, and Europe. China produced approximately 20 million units of masks a day, which was approximately half the global production capacity for masks [5]. According to the U.S. Department of Health and Human Services, the U.S. imports 95\% of its surgical masks and 70\% of its respirators [7].

Quality control is essential for FFRs to protect their wearers. Certification is required for manufacturers to sell their FFRs in major markets. The certified protection level is often represented in the product names. For example, N95 represents the filtering ability of at least $95 \%$ of the airborne particles. The National Institute for Occupational Safety 
and Health (NIOSH) manages the N95 certification process in the U.S. [14]. The N95 certification process takes approximately three months from submittal to approval [15].

The end users acquire masks through two types of distribution channels. Institutional consumers, such as hospitals and manufacturing firms, procure the masks in business-tobusiness transaction channels and distribute them to their employees according to their needs. In this case, the contract is settled through a negotiation process between the buyer and the manufacturer. Individual consumers purchase masks from retail pharmacies. The transactions depend on the market mechanism.

There is little consensus on how much demand should be fulfilled. For example, various estimations of the demand in the U.S. have been provided. Assuming a 42-day severe influenza pandemic, the U.S. CDC estimated a need for at least 1.5 billion medical masks for the healthcare sector and 1.1 billion for the public. In addition, the healthcare sector will demand more than 90 million N95 respirators [16]. Carias et al. [17] estimate the maximum demands at 7.3 billion respirators and 0.04 billion surgical masks for healthcare institutes in the U.S. In March 2020, the U.S. Department of Health and Human Services estimated that U.S. healthcare workers would need 300 million N95 respirators per month to fight a pandemic [18]. The estimations for the healthcare sector vary to a significant extent, and estimations for the public are rare.

\subsection{The Disaster Management Cycle}

Disaster management has been intensively studied because of the serious effects of disasters and the difficulty in containing them. Disasters refers to "events that occur when significant numbers of people are exposed to hazards to which they are vulnerable, with resulting injury and loss of life, often combined with damage to property and livelihoods" [19]. Disasters cause crises, which are "the perception of an unpredictable event that threatens important expectancies of stakeholders and can seriously impact an organization's performance and generate negative outcomes" [20]. Both disaster management and crisis management agree on the four interrelated phases: preparation, response, recovery (revision), and mitigation (prevention). As depicted in Figure 2, a disaster management cycle refers to repeating the four steps to manage the severe impact of a disaster.

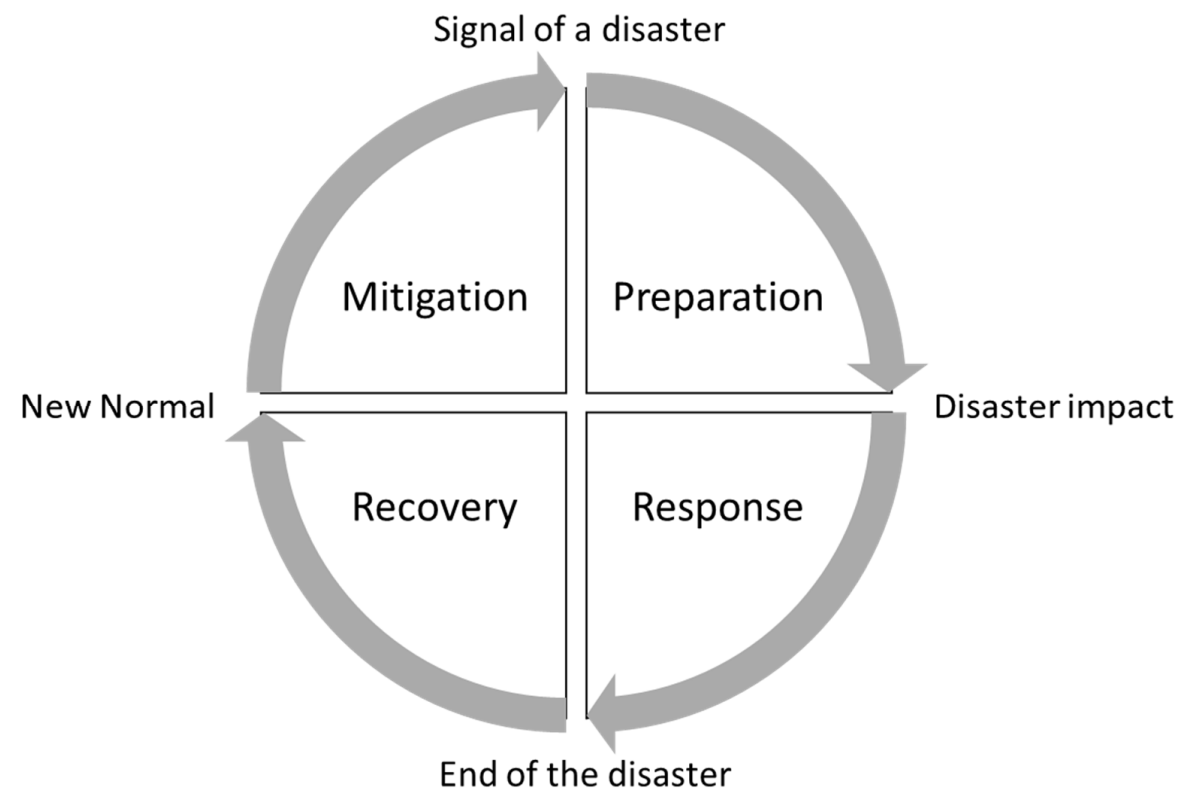

Figure 2. Disaster management cycle.

The disaster management cycle has been used in many studies to explore extreme events and management practices, and public affairs. For example, Basri et al. [21] conducted survey research to explore disaster management cycle of a flood event in Malaysia from the perspective of industry players and flood victims. Based on the four 
stages of the disaster management cycle, Sim et al. [22] employed in-depth interviews to develop competence and skill sets of social workers for the field of disaster management in China. Recently, Thyagarajan et al. [23] applied the disaster management cycle to describe the development, implementation, and outcomes of a national-scale simulation delivery platform in response to the COVID-19 pandemic disaster. This platform is developed by India's Pediatric Simulation Training and Research Society. Their research presented how this platform enabled the management team to address key aspects of the disaster management cycle. The disaster management cycle has been confirmed as an effective approach to encompass preparation for and recovery from large-scale disasters.

In advance of the evident threat of a respiratory disease pandemic, the mitigation phase comprises designing and constructing an FFR supply chain that decreases the impacts of the disaster on society and the environment.

When the threat of a respiratory disease pandemic is observed but the disease has not yet impacted society, the preparation phase includes activities to organize and to allocate resources along the FFR supply chain to provide the product where it is needed during the pandemic. The tasks in the preparation phase are relatively short-term proactive compared to the tasks in the mitigation phase. The preparation phase continues some tasks from the mitigation phase, such as vulnerability assessment, constructing an information sharing system, estimating the supply chain capacity, diversifying suppliers, and constructing an FFR stockpile. In this section, we discuss the other additional tasks in the preparation phase.

Once the pandemic impacts society, the response phase consists of rapid and effective actions to provide the FFRs to reduce the damage from the disaster. When the supply chain is efficiently designed and constructed in the mitigation and preparation phases, the reaction will be more effective than the case for COVID-19.

After the pandemic, the recovery phase involves the actions taken to return to a new normal situation such as returning the supply chain resources to an efficient allocation for to meet normal demands.

\section{Conceptual Model of FFR Supply Chain Management Based on the Disaster Management Cycle}

To build an effective FFR supply chain to cope with a disastrous situation such as the COVID-19 pandemic, it is necessary to integrate existing and proposed supply chain management strategies based on the disaster management principle.

We propose an implementable FFR supply chain management framework based on the disaster management cycle. Figure 3 illustrates the overview of our framework. Compared to existing articles that focus on increasing the production capacity, our framework considers four pillars: information, production, distribution, and sustainability. The unique feature of this paper is the systematic integration of multidimensional supply chain management strategies over the four phases of the disaster management cycle.

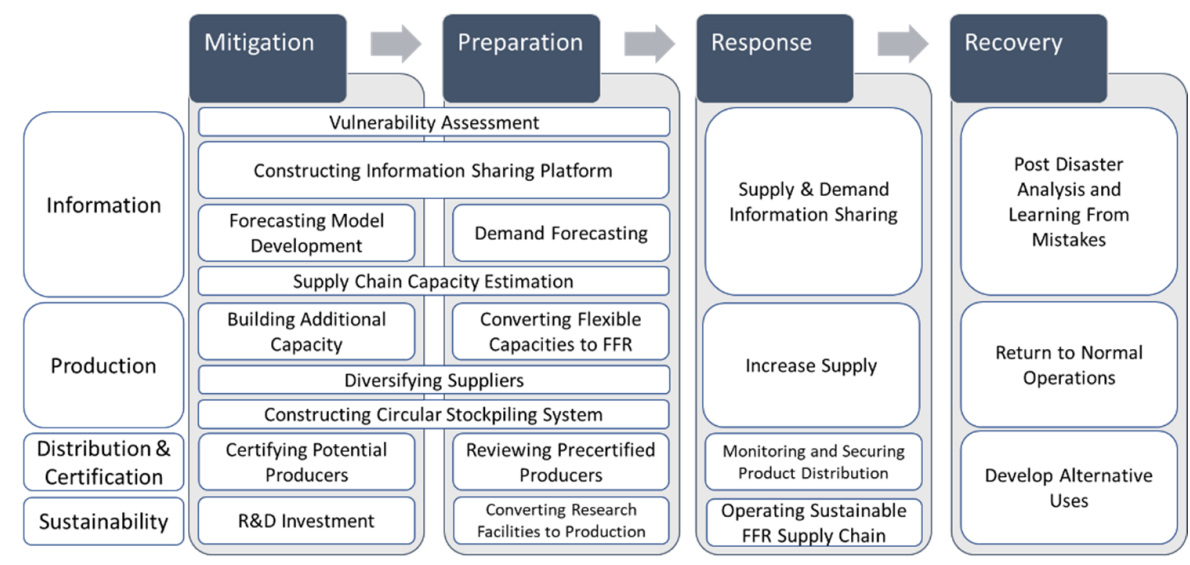

Figure 3. FFR supply chain management framework based on the disaster management cycle. 


\subsection{Mitigation Phase}

\subsubsection{Vulnerability Assessment}

In terms of FFR supply chain management, a vulnerability assessment identifies the anticipated bottlenecks that the supply chain will face [10]. For example, Rice [24] states that too high a concentration of suppliers in China is the most critical vulnerability. However, there is little consensus about the lack of diversification being the most important obstacle. For instance, Gereffi [25] asserts that the MB filter supply shortage is the primary problem of the FFR supply during the COVID-19 pandemic.

Considering the huge and continuous demand for FFRs, it is necessary to conduct a vulnerability assessment of various aspects of the entire supply chain. According to the theory of constraints, a bottleneck is the least capable tier of a supply chain that restricts the entire supply chain capacity [26]. This theory implies that every tier in the FFR supply chain should have enough capacity to meet the demand. Because multiple processes of the current FFR supply chain do not have enough capacity to meet the huge and continuous demand, researchers have presented various opinions on the vulnerability assessment. Diversified vulnerability assessments are desirable to identify various potential bottlenecks.

Vulnerability assessments are essential in the mitigation and preparation phases because they form the basis to construct an effective FFR supply chain. A vulnerability assessment calls for follow-up actions such as source diversification and increasing the MB filter supply. Because it takes considerable time to implement the follow-up actions, we should conduct this task in the mitigation phase or at least in the preparation phase.

\subsubsection{Constructing an Information Sharing and Monitoring Platform}

Under unexpected disastrous situations, we cannot overemphasize the importance of using information to make decisions to reduce the damage from disasters. Efficient information sharing is one common aspect of the countries that successfully contained the COVID-19 outbreak such as South Korea and Taiwan $[4,27,28]$. The governments of these countries control the supply of FFRs and provide the supply chain data to the public. The data include the import and production of the components (such as MB filters) and final products and the FFR inventory of retail shops. The manufacturers and retail shops collaborate with the government to update the data on time.

The information-sharing platform can be used for material flow monitoring [9]. For example, the infiltration of fake FFRs and underperforming materials into the FFR supply chain is a significant problem [29]. Researchers suggest blockchain as a tool to secure the supply chain from illegitimate products $[30,31]$. It is a critical task in the mitigation phase to construct an information-sharing platform utilizing advanced information technologies that can be used for supply chain monitoring.

\subsubsection{Developing a Forecasting Model}

It is essential to develop a forecasting model for FFR demands during a disastrous situation. The scope of the forecasting model includes not only the independent demand for the final product, but it also includes the derived demand for the components. Despite the estimation of the demand for the final product during the COVID-19 pandemic, it is rare that the demand for other components such as MB filters, manufacturing processes, and quality certification processes be estimated. Because it is a requirement to manage the entire supply chain, the forecasting model should be informative for every tier of the supply chain.

The forecasting model should be able to reflect the updated data through the information sharing system. As we can see in South Korea's case, the dynamic forecasting model forms the basis of societies' proactive strategies against the disastrous situation [28]. The possible models include scenario-based forecasting models, stress test models, and artificial intelligence algorithms [27,32,33]. 


\subsubsection{Supply Chain Capacity Estimation}

As we show with the FFR supply chain capacity before the pandemic section, the FFR supply capacity estimation requires identifying each tier's capacity and the bottleneck of the supply chain. For example, during the COVID-19 pandemic, the production capacity bottleneck has been the MB filter supply capacity $[8,18]$. It is impossible to increase the FFR supply without identifying the bottleneck. Moreover, a finer estimation of each tier's capacity allows one to conduct risk assessments such as the what-if test. For example, we can answer the question "when a part of supply chain is disrupted, how much supply can we acquire?" by identifying the bottleneck under the postulated scenario.

\subsubsection{Build Additional Flexible Capacity}

To fill the supply and demand gap, capacity expansion is a straightforward strategy. Reacting to the COVID-19 outbreak, huge capital investments have been made to build additional FFR production capacity. For example, the U.S. Department of Defense (DOD) invested \$133 million in domestic N95 mask production. Through the investment, three major companies, 3M, O\&M Halyward, and Honeywell, will produce 37.5 million masks per month after initialization [34].

Because capacity expansion takes considerable time, it is part of the mitigation phase. For example, Reicofil is a German manufacturer of the machinery used to make MB filters. The company can establish a melt-blown production line in less than four months. This is an expedited timeframe to cope with the COVID-19 pandemic [35]. This implies that effective capacity expansion requires well-developed plans and accurate forecasting. Researchers use the real options approach and stochastic control theory to determine the investment timing and size [36,37].

When the capacity is expanded, how to utilize the expanded capacity after the crisis should be considered. For example, Medicom Group, a Montreal-based company, opened an FFR factory in Canada. The company and the Canadian government made a long-term agreement about after pandemic FFR supply. Medicom's chief executive, Ronald Reuben, stated that the long-term agreement was crucial for the investment decision [18]. Without a plan to handle the excess capacity, much of the capacity will be idle after the pandemic.

The additional capacity should be flexible so that it can be utilized to meet regular demands for other products. During the COVID-19 pandemic, suppliers increase the mask material supply by modifying their similar production lines to mask filter production lines. From the production technology viewpoint, mask MB filters are similar to absorbent hygiene products. Therefore, diaper and feminine hygiene producers can change their production lines to mask MB filter lines. For example, Procter and Gamble (P\&G) converted approximately 10 absorbent hygiene product production lines to mask material production lines in reaction to COVID-19 outbreak [35]. If the converted capacity can be returned to their usual production mode, we can avoid a considerable amount of inefficient capacity.

\subsubsection{Developing Diversified Sources}

It is essential to diversify the FFR sources to mitigate the supply disruption risk for concentrated sources. If sourcing options are concentrated in a specific region, disruptions at the location put the entire supply chain at risk [38]. The COVID-19 spread started to be serious in Wuhan, China. Due to the surging demand, China prohibited FFR exports to satisfy the domestic demand first. Because China retained approximately $50 \%$ of the FFR production capacity, many countries suffered FFR supply disruptions in the early stage of the COVID-19 pandemic.

If the sources are diversified, the risk of disrupting all the diversified sources is significantly lower than the case of a concentrated source. Therefore, countries have sought to develop alternative FFR suppliers. For example, Tajikistan, where no COVID-19 cases had been reported until early April 2020, became an alternative mask production country that provides masks to other countries [39]. A supply chain redesign with second sources and a redesign to local sources are possible options for source diversification [10]. Researchers in 
the operations management area have studied the optimal level of diversification considering the costs and benefits $[40,41]$.

We remark that nondiversifiable risk exists, and source diversification should be integrated with other strategies. Although it has been regarded as a rare event, sourcing diversification is ineffective when all the sources are disrupted by a super event [40]. Unfortunately, the COVID-19 pandemic is a super event. Approximately 80 countries prohibited or restricted the export of COVID-19 products by the end of April 2020 [42]. Because the 80 countries include most of the FFR suppliers, supplier diversification has limited effect in managing a disastrous event such as the COVID-19 pandemic. This implies that source diversification should be a part of the solution in a systematic framework.

\subsubsection{Constructing a Circular Stockpiling System}

Inventory stocking is a traditional solution to cope with high demand. Many countries stockpile medical devices to counter potential threats. For example, the U.S. Strategic National Stockpile system stores vaccines, antiviral drugs, and PPE to cope with public health emergencies, such as large-scale pandemics and natural disasters. Canada, Australia, and Finland also operate similar systems $[43,44]$.

Because FFRs are perishable items, the stockpile and rotation systems of Singapore and Taiwan provide valuable managerial insights. The functionality of FFRs deteriorates over time [45]. To prevent obsoletion, Singapore and Taiwan periodically replace old items with new items if no threats occur [44]. The old, replaced items are consumed by medical institutions. By maintaining the FFR stockpiling system during the mitigation phase, society can cope with a sudden outbreak of a contagious respiratory disease pandemic.

Stockpiling should be a part of a systematic solution because it provides a temporary buffer until other strategies are effectively exercised. The COVID-19 pandemic has lasted longer than the stockpiles lasted, even for countries that operate a large-scale stockpiling system. Therefore, countries source additional FFRs from alternative sources [46]. Although the stockpile does not cope with the entire demand for a pandemic, it provides valuable time to exercise other strategies because the inventory can be used instantaneously. For example, society can use the FFR inventory while it converts a diaper production line to the FFR production mode. Stockpiling plays a critical role as the buffer to reduce the impact of a sudden shock in the FFR supply chain management framework.

\subsubsection{Certifying Potential Producers}

In the mitigation phase, certification authorities need to certify potential FFR suppliers. During the COVID-19 pandemic period, underperforming and fake masks were traded [29]. The certification process takes considerable time although it provides valuable information about the product quality to consumers. A possible solution is certifying potential FFR producers during the mitigation phase. By certifying the potential production capacity in advance, society can timely acquire confirmed FFRs during an emergency.

\subsubsection{Research and Development for a Sustainable FFR Supply Chain}

Designing and building a sustainable FFR supply chain is an urgent request and requires aggressive investment in research and development (R\&D). Regarding FFR production technologies, the impending R\&D topics include durable FFR development, recycling technologies, waste treatment technologies, and a reverse logistics design. The current FFRs are designed to be disposable. Therefore, huge waste continuously occurs during a pandemic, and it causes a serious problem to our ecosystem [47,48]. If a durable FFR protects the wearer from virus transmission, it will dramatically reduce the production burden and the medical waste. If a used FFR can be disinfected while maintaining a reasonable protection ability, we can expect a similar benefit [49]. Another imminent research topic is how to design a closed-loop FFR supply chain that encompasses a reverse logistics system to manage the used FFRs. The used FFRs are a plastic medical waste that should be disposed of carefully. This implies that treating the used FFRs requires specialized systems to reduce 
the harmful effects on our ecosystem [50]. Finding the optional locations and capacities of the waste treatment facilities to build the reverse logistics system is a requirement [51].

$R \& D$ investment is worthwhile because R\&D facilities can be converted to supply bases during a pandemic. For example, North Carolina State University produces face mask material using their research facilities [52]. The University of Missouri utilizes their research facility to cut the mask materials [53]. Skoltech FabLab, a Russian research facility, produces PPE for hospitals in Moscow [54]. Because many research facilities belong to nonprofit organizations, they are willing to form a cooperative societal effort to overcome the emergency. R\&D investment is a strategy to build a cooperative emergency supply base.

\subsection{Preparation Phase}

\subsubsection{Demand Forecasting}

Using the forecasting model developed in the mitigation phase, the demand for FFR should be estimated based on the data about the impending disaster. This task includes adjusting model assumptions, selecting appropriate scenarios, and numerical calculations. Moreover, risk assessments, such as stress tests, are essential to building reaction strategies [55]. In the preparation phase, the demand for FFRs is estimated under the specific model for the imminent disaster including the uncertainty assessment for the demand.

\subsubsection{Converting Flexible Capacity to FFR Supply Capacity}

The preparation phase is the best time to convert production with flexible capacities to the FFR supply capacity. Production line conversion is well-known to operations managers as production flexibility. The flexible capacities include research facility capacities, manufacturing process (such as cutting and knitting) capacities, and the absorbent $\mathrm{MB}$ fiber capacities that can be converted to the FFR MB filter production process.

It takes time to establish a new production process and train workers for FFR production. For example, P\&G had to install new equipment or adjust existing equipment to change its production mode. Moreover, the employees need to be trained for the new production process. $P \& G$ collaborated with their business partners to reduce the friction from changing systems [35]. Considering the conversion time delay and the demand estimation, the preparation phase coordinates the order of the flexible processes to be converted to FFR production, the timing of exercising the flexibility option, and the magnitude of the production capacity. These decision problems have been an intensive research topic in operations management and industrial engineering [56]. By utilizing the accumulated knowledge, flexible capacities should be efficiently reallocated to cope with the approaching disaster.

\subsubsection{Renewing the Precertified Suppliers}

When precertified suppliers convert their production lines to FFR production, they must renew their quality certification. The renewal process should be faster than the regular certification process and effective enough to ensure the produced FFR's protection capability. For a new producer that has not been certified, the regular certification process should be imposed.

\subsection{Response Phase}

\subsubsection{Supply and Demand Information Sharing}

An efficient information flow is beneficial to stakeholders to make better decisions. For example, the Korean Ministry of Food and Drug Safety (MFDS) provided the FFR production, consumption, and inventory data to the public every day during the COVID-19 pandemic. The data help producers to determine their production rates and to comply with the government's control policy. The public can find where to buy FFRs in real time through mobile apps [57]. A sharp contrast to South Korea's successful case is the U.S.'s case. In the U.S., all the FFR supply chain data are confidential except for the manufacturing facility locations, and even the nationwide FFR supply data are closed to the public [55]. 
The lack of data transparency hinders the abilities of governments, hospitals, and other stakeholders to assess and to respond to the FFR supply disruption risk in the U.S. during the COVID-19 pandemic.

The shared information forms the basis of trust among the stakeholders and results in societal collaboration to cope with emergencies. The public and private sectors of South Korea effectively collaborate to fight COVID-19 based on the trust based on transparent information sharing $[4,28]$. Hong Kong successfully contained the spread of COVID-19 through the community's voluntary information sharing and collaboration [58]. The China Aid organization utilizes a blockchain to increase trust and transparency [59]. On the other hand, Italy and the U.S. had difficulties coordinating resources due to insufficient trust among decision makers, even though the coordination mechanisms are formal [60]. These cases illustrate the importance of transparent and active information sharing in the response phase.

\subsubsection{Increase FFR Supply}

To fulfil the sudden, huge, and continuous demand for FFRs, we need to fully utilize the options for increasing the FFR supply developed in the mitigation and preparation phases. Considering the costs and time to implement the strategies, the order of the strategies is: (1) consuming the stored FFR inventories, (2) sourcing from diversified suppliers, (3) increasing the production rate within the existing capacity, (4) converting more flexible capacity to FFR supply, and (5) building additional capacity. If the demand for FFRs is within the estimation made in the preparation phase, the demand would be fulfilled with the first three options. If the demand exceeds the forecasted level, however, implementing the last two options should be considered.

\subsubsection{Monitoring and Securing Product Distribution}

In the response phase, it is necessary to distribute the qualified FFRs to consumers at a reasonable price. The COVID-19 pandemic illustrates challenges for this task: (1) qualifying a large number of products in a short amount of time, (2) preventing hoarding and panic buying, and (3) securing the distribution channels from being infiltrated by fake products and underperforming products. The strategies we discussed in the mitigation and preparation phases are premises to overcome these challenges.

There is a dilemma between quality assurance and timely supply. To be able to have an agile reaction against the COVID-19 outbreak, expediting quality certification processes is a common action that many authorities in the world implement. For instance, the U.S. Food and Drug Administration (FDA) operates Emergency Use Authorizations (EUAs) that allow "unapproved medical products or unapproved uses of approved medical products to be used in an emergency to diagnose, treat, or prevent serious or life-threatening diseases or conditions caused by CBRN (Chemical, Biological, Radiological and Nuclear) threat agents when there are no adequate, approved, and available alternatives [61]." The FDA includes FFRs in the EUA program and presents the information on approved items on its webpage. However, Plana et al. [29] examined the quality of the FFRs that are approved under EUA. The test results show that "Many did not perform to accepted standards and are likely to be counterfeit." It is an urgent and difficult task to construct a trustworthy supply chain under emergencies.

To mitigate the certification delay, it is effective to utilize precertified suppliers and research facilities. For the precertified suppliers in the mitigation phase, the certification process is unnecessary or reduced. The research facilities can participate in the certification process to reduce the burden on the certification authorities. Utilizing these devices can increase the capacity of the potential bottleneck of the FFR supply chain.

When necessary goods are in short supply, market-based transactions may result in prices soaring, panic buying, hoarding, and counterfeits. It is not surprising that we observe these phenomena in the FFR market during the COVID-19 pandemic [62-64]. On the other hand, South Korea, Taiwan, and Singapore successfully control their FFR 
distribution, which is one of the critical ways that those countries successfully curbed the spread of the disease.

By utilizing the information sharing system that is constructed in the mitigation phase, governments can control the FFR material flows to prevent hoarding and panic buying. For example, the Korea Public Procurement Service (KPPS) procured masks from producers and distributed them to the public. The masks distributed in this channel are called public masks. KPPS controlled both the unit price of the public masks at approximately $\$ 1.20$ and the maximum number that could be bought per week according to the supply [28]. Korean citizens could find where to buy the public masks using a mobile phone app in real time $[57,65]$. The South Korean government successfully led the public to curb the spread of COVID-19 spread by utilizing the product distribution control and the real-time inventory information app.

Although actual application cases are rare, researchers suggest the blockchain and artificial intelligence as the tools to secure the supply chain from underperforming and fake products. Orcutt [66] asserts that the blockchain enhances transparency in supply chain tiers so that it can prevent a supply chain network failure. The China Aid organization has implemented a blockchain system, and pharmaceutical supply chains are conducting pilot studies on blockchain systems [59,67]. The information sharing system equipped with advanced technologies can assist in securing the FFR distribution channels $[68,69]$.

\subsubsection{Operating a Sustainable FFR Supply Chain}

Even though a well-designed sustainable FFR supply chain has been constructed, it is still challenging to operate the chain in the response phase. For example, after members of the public use masks, they dispose of the used masks at home. How can the waste from individual households be collected and put into a sustainable supply chain? Despite the increasing volume of research on sustainable FFR supply chains, solutions to this question are limited [70].

\subsection{Recovery Phase}

\subsubsection{Post Disaster Analysis and Learning from Mistakes}

The lessons learned from previous mistakes are valuable. One factor of Asian countries' successful reaction is that they learned costly lessons from previous respiratory disease outbreaks such as severe acute respiratory syndrome (SARS) in 2003 and Middle East respiratory syndrome (MERS) 2015 [4]. The abundant data that are gathered through the information-sharing system must be analyzed. Post-event data analysis should answer the following important questions:

1. What was the valuable information that the information-sharing system did not include?

2. What were the demand forecasting errors and why did forecasting errors occur?

3. What was the gap between the estimated supply capacity and the actual supply and why do supply estimation errors occur?

4. Did the FFR distribution deliver satisfactory quality products at a reasonable price on time? If not, what was the problem that disturbed the distribution channels?

5. Were there effective and innovative FFRs? If so, how can they be incorporate the new FFRs in the certification process?

6. What were the situations that the developed plan did not cover?

By answering these critical questions to assess the key performance of each tier, we can acquire insights to improve the disaster management strategies.

\subsubsection{Returning Flexible Capacities to Normal Operations}

As the pandemic diminishes, the demand for FFRs declines. This is the time for the flexible FFR production capacities to return to their original businesses. For example, there can be back orders for products such as water filters, diapers, and feminine hygiene products. By returning the FFR production capacities to these products, we can avoid 
inefficient redundant capacity maintenance. Because of this property, flexibility is often regarded as a synonym of resilience.

\subsubsection{Develop Alternative Uses}

Developing alternative uses for the FFR production capacities is necessary if excessive capacities still exist after reallocating the flexible capacities. Without developing alternative demand, the industry does not maintain the redundant capacity, and this will result in supply deficiencies in future disasters. Moreover, the public and private sector agreements may include the government's support for the FFR producers after the disaster [18]. Therefore, how to handle the excessive but necessary capacities is an important issue in the recovery phase.

Demand development requires both the public and private sectors to be creative, and it is desirable to generate constant demands for FFR related products. For example, the MB filter production capacity can be modified to produce water filters. By providing water purification systems to public schools, the government can generate ongoing demand to maintain the flexible capacity for the FFR.

\subsection{Discussion}

There are limitations of this study that provide future research directions. First, we restrict our interest to FFR supply chain management. To curb disease outbreaks, the public's willingness to wear masks is essential. However, our discussion does not include how to get the public to wear masks. Wearing masks is effective when combined with other strategies such as aggressive testing, infection path tracking, and appropriate patient quarantines. Therefore, our framework is a part of a wider framework. We hope that our paper contributes to building a society safer from diseases.

Second, extended qualitative studies based on this conceptual model will be valuable to enhance our understanding of effective strategies for managing disaster situations. Interviews and focus groups should be conducted among FFR supply chain members to provide practical insights.

Third, empirical studies may be developed to offer quantitative estimation and prediction of the supply and demand of FFR. Trade data of raw materials and finished FFR products can be incorporated to understand the dynamics of the FFR supply chain on a global scale.

Last, our framework can be more efficient through global cooperation. However, the international partnership has not been discussed enough. For example, future research can investigate how much value can be created when developed countries establish a forecasting system and share the information with other underdeveloped countries. The future research topic can include the priority and emphasis of resource allocation according to the country's development phase.

\section{Conclusions}

This paper provides a framework to manage the FFR supply chain when reacting to a disastrous situation such as the COVID-19 pandemic. We provide implementable strategies based on the disaster management cycle that includes the mitigation, preparation, response, and recovery phases. Based on the four pillars, this conceptual framework demonstrated major topics in four phases of the disaster management cycle. Each point was discussed by presenting examples and current practices. The mitigation phase focuses on building an information-sharing infrastructure, developing a demand forecasting model, evaluating the supply chain capacity, constructing various supply bases, and creating contingency plans by forming a social consensus. The preparation phase takes short-term proactive actions such as forecasting the demand and converting flexible capacities into FFR production. In the response phase, all available resources are mobilized to increase the supply to meet the growing demand. Securing the distribution channels is also critical in the response phase. After the disaster, it is a painful but necessary step to reflect on the past event to 
learn from any failures. In addition, managing the increased FFR supply chain capacity is essential to sustaining the emergency reaction capability in the supply chain. We developed a framework based on an intensive literature review. We hope that our paper contributes to mitigating future pandemics. Policy makers, healthcare sectors, stakeholders throughout FFR supply chain may establish a database and monitoring system to respond such urgent events in the future.

Author Contributions: Conceptualization, K.K. and L.Z.; writing—original draft preparation, K.K.; writing - review and editing, K.K. and L.Z. All authors have read and agreed to the published version of the manuscript.

Funding: This research received no specific grant from any funding agency in the public, commercial, or not-for-profit sectors.

Data Availability Statement: No new data were created or analyzed in this study. Data sharing is not applicable to this article.

Acknowledgments: We thank Jung E. Ha-Brookshire for the helpful comments for this research project. We also thank the anonymous reviewers and the editors for the constructive comments to improve this manuscript.

Conflicts of Interest: The authors declare no conflict of interest.

\section{References}

1. Chu, D.K.; Akl, E.A.; Duda, S.; Solo, K.; Yaacoub, S.; Schünemann, H.J.; El-harakeh, A.; Bognanni, A.; Lotfi, T.; Loeb, M.; et al. Physical distancing, face masks, and eye protection to prevent person-to-person Transmission of SARS-CoV-2 and COVID-19: A systematic review and meta-Analysis. Lancet 2020, 395, 1973-1987. [CrossRef]

2. MacIntyre, C.R.; Seale, H.; Dung, T.C.; Hien, N.T.; Nga, P.T.; Chughtai, A.A.; Rahman, B.; Dwyer, D.E.; Wang, Q. A cluster randomised trial of cloth masks compared with medical masks in healthcare workers. BMJ Open 2015, 5, e006577. [CrossRef]

3. Howard, J.; Huang, A.; Li, Z.; Tufekci, Z.; Zdimal, V.; van der Westhuizen, H.-M.; von Delft, A.; Price, A.; Fridman, L.; Tang, L.-H.; et al. Face mask against COVID-19: An evidence review. Br. Med. J. 2020, 1-8. [CrossRef]

4. Moon, M.J. Fighting COVID-19 with agility, transparency, and participation: Wicked policy problems and new governance challenges. Public Adm. Rev. 2020, 80, 651-656. [CrossRef] [PubMed]

5. Park, C.-Y.; Kim, K.; Roth, S.; Beck, S.; Kang, J.W.; Tayag, M.C.; Grifin, M. Global Shortage of Personal Protective Equipment amid COVID-19: Supply Chains, Bottlenecks, and Policy Implications; Asian Development Bank: Manila, Philippines, 2020.

6. Ranney, M.L.; Griffeth, V.; Jha, A.K. Critical supply shortages-The need for ventilators and personal protective equipment during the Covid-19 pandemic. N. Eng. J. Med. 2020, 382, E41. [CrossRef] [PubMed]

7. McKenna, M. Amid Coronavirus Fears, a Mask Shortage Could Spread Globally. Available online: https://www.wired.com/ story/amid-coronavirus-fears-a-mask-shortage-could-spread-globally / (accessed on 3 August 2020).

8. Yu, H. 3M Makes a Lot of Masks But Trump Can't Increase Its Supply. Available online: https://www.forbes.com/ sites/howardhyu/2020/04/03/3m-makes-a-lot-of-masks-but-trump-cant-increase-its-supply/\#793e98053596 (accessed on 3 August 2020).

9. Linton, T.; Vakil, B. Coronavirus Is Proving We Need More Resilient Supply Chains. Available online: https://hbr.org/2020/03/ coronavirus-is-proving-that-we-need-more-resilient-supply-chains (accessed on 12 August 2020).

10. Shih, W. Global supply chains in a post- pandemic world companies need to make their networks more resilient. Here's how. Harv. Bus. Rev. 2020, 95, 82-90.

11. Atkinson, C.L.; McCue, C.; Prier, E.; Atkinson, A.M. Supply chain manipulation, misrepresentation, and magical thinking During the COVID-19 pandemic. Am. Rev. Public Adm. 2020, 50, 628-634. [CrossRef]

12. Kalil, B. COVID-19 SUPPLY \& Demand-International Fiber Journal. Available online: https://fiberjournal.com/covid-19 -supply-demand/ (accessed on 3 August 2020).

13. Rousse, D. Achieving US Self-Sufficiency on Meltblown Fabric for Facemasks. Available online: https://fiberjournal.com/ achieving-us-self-sufficiency-on-meltblown-fabric-for-facemasks / (accessed on 3 August 2020).

14. NIOSH Approved N95 Respirators Particulate Filtering Facepiece Respirators. Available online: https:/ /www.cdc.gov/niosh/ npptl/topics/respirators/disp_part/n95list1-a.html (accessed on 7 August 2020).

15. Birkner, J. Detailing the process for NIOSH respirator approval. Saf. Health 2006, 173, 52.

16. Institute of Medicine Reusability of Facemasks during an Influenza Pandemic: Facing the Flu; National Academies Press: Washington, DC, USA, 2006.

17. Carias, C.; Rainisch, G.; Shankar, M.; Adhikari, B.B.; Swerdlow, D.L.; Bower, W.A.; Pillai, S.K.; Meltzer, M.I.; Koonin, L.M. Potential demand for respirators and surgical masks during a hypothetical influenza pandemic in the United States. Clin. Infect. Dis. 2015, 60, S42-S51. [CrossRef] 
18. Hufford, A. 3M CEO on N95 Masks: 'Demand Exceeds Our Production Capacity'. Available online: https://www.wsj.com/ articles/3m-ceo-on-n95-masks-demand-exceeds-our-production-capacity-11585842928 (accessed on 7 August 2020).

19. Wisner, B.; Adams, J.; World Health Organization (WHO). Environmental Health in Emergencies and Disasters: A Practical Guide / Edited by B. Wisner, J. Adams; World Health Organization: Geneva, Switzerland, 2002.

20. Coombs, W. Timothy. Ongoing Crisis Communication: Planning, Managing, and Responding; SAGE Publications: Thousand Oaks, CA, USA, 2014

21. Basri, S.A.A.; Zakaria, S.A.S.; Majid, T.A.; Yusop, Z. Exploring awareness and application of disaster risk management cycle (drmc) from stakeholder's perspective. Int. J. Disaster Resil. Built Environ. 2021. preprint. [CrossRef]

22. Sim, T.; Cui, K.; Tan, Z.; Yan, E.; He, M. Against the odds: Developing a core competence framework of social work practice for the field of disaster management in China. Impact 2021, 2021, 9-11. [CrossRef]

23. Thyagarajan, S.; Ramachandra, G.; Jamalpuri, V.; Calhoun, A.W.; Nadkarni, V.; Deutsch, E.S. Simulathon 2020: Integrating simulation period prevalence methodology into the COVID-19 disaster management cycle in India. Simul. Healthc. J. Soc. Simul. Healthc. 2021. [CrossRef] [PubMed]

24. Rice, J.B., Jr. Prepare Your Supply Chain for Coronavirus. Harvard Business Review, 7 February 2020.

25. Gereffi, G. What does the COVID-19 pandemic teach us about global value chains? The case of medical supplies. J. Int. Bus. Policy 2020, 3, 1-15. [CrossRef]

26. Schroeder, P. The goal: A process of ongoing improvement. J. Nurs. Care Qual. 1994, 8, 83. [CrossRef]

27. Hsieh, C.C.; Lin, C.H.; Wang, W.Y.C.; Pauleen, D.J.; Chen, J.V. The outcome and implications of public precautionary measures in Taiwan-Declining respiratory disease cases in the COVID-19 pandemic. Int. J. Environ. Res. Public Health 2020, $17,4877$. [CrossRef]

28. Lee, E.; Chen, Y.-Y.; McDonald, M.; O’Neill, E. Dynamic response systems of healthcare mask production to COVID-19: A case study of Korea. Systems 2020, 8, 18. [CrossRef]

29. Plana, D.; Tian, E.; Cramer, A.K.; Yang, H.; Carmack, M.M.; Sinha, S.; Bourgeois, F.T.; Yu, S.H.; Masse, P.; Boyer, J.; et al. Assessing the quality of nontraditional N95 filtering face-piece respirators available during the COVID-19 pandemic 2 . medRxiv 2020. preprint. [CrossRef]

30. Van Hoek, R.; Lacity, M. How the pandemic is pushing blockchain forward. Harv. Bus. Rev. 2020, 7, 1-7.

31. Yoon, J.; Talluri, S.; Yildiz, H.; Sheu, C. The value of blockchain technology implementation in international trades under demand volatility risk. Int. J. Prod. Res. 2020, 58, 2163-2183. [CrossRef]

32. Di Vaio, A.; Boccia, F.; Landriani, L.; Palladino, R. Artificial Intelligence in the agri-food system: Rethinking sustainable business models in the COVID-19 scenario. Sustainability 2020, 12, 4851. [CrossRef]

33. Ivanov, D. Predicting the impacts of epidemic outbreaks on global supply chains: A simulation-based analysis on the Coronavirus outbreak (COVID-19/SARS-CoV-2) case. Transp. Res. E Logist. Transp. Rev. 2020, 136, 101922. [CrossRef] [PubMed]

34. US Department of Defense DOD Details $\$ 133$ Million Defense Production Act Title 3 COVID-19 Project. Available online: https: / / www.defense.gov/Newsroom/Releases/Release/Article/2158351/dod-details-133-million-defense-productionact-title-3-covid-19-project/ (accessed on 9 August 2020).

35. McIntyre, K. Nonwovens Supply Shifts. Available online: https://www.nonwovens-industry.com/issues/2020-05/view_ features/nonwovens-supply-shifts / (accessed on 3 August 2020).

36. Kim, K.; Deshmukh, A. Effect of investment and disinvestment delay in biofuels. Int. J. Real Options Strategy 2018, 6, 1-11. [CrossRef]

37. Elsanosi, I.; Øksendal, B.; Sulem, A. Some solvable stochastic control problems with delay. Stochastic Rep. 2000, 71, 69-89. [CrossRef]

38. Sturgeon, T.; van Biesebroeck, J.; Gereffi, G. Value chains, networks and clusters: Reframing the global automotive industry. J. Econ. Geogr. 2008, 8, 297-321.

39. Arthur, C. (United N.I.D.O. COVID-19: UNIDO Helps Tajik Textile Enterprises Diversify into PPE Production. Available online: https: / / www.unido.org/stories/covid-19-unido-helps-tajik-textile-enterprises-diversify-ppe-production (accessed on 3 August 2020).

40. Berger, P.D.; Gerstenfeld, A.; Zeng, A.Z. How many suppliers are best? A decision-analysis approach. Omega 2004, 32, 9-15. [CrossRef]

41. Tang, C.; Tomlin, B. The power of flexibility for mitigating supply chain risks. Int. J. Prod. Econ. 2008, 116, 12-27. [CrossRef]

42. World Trade Organization (WTO) Export Prohibitions and Restrictions. Available online: https://www.wto.org/english/tratop_ e/covid19_e/export_prohibitions_report_e.pdf (accessed on 8 August 2020).

43. Anderson, C.; Libell, H.P. Finland, 'prepper nation of the Nordics,' isn't worried about masks. New York Times, 5 April 2020.

44. Chen, Y.J.; Chiang, P.J.; Cheng, Y.H.; Huang, C.W.; Kao, H.Y.; Chang, C.K.; Huang, H.M.; Liu, P.Y.; Wang, J.H.; Chih, Y.C.; et al. Stockpile model of personal protective equipment in Taiwan. Health Secur. 2017, 15, 170-174. [CrossRef]

45. Rottach, D.R.; Lei, Z. Stockpiled N95 filtering facepiece respirator polyisoprene strap performance. J. Int. Soc. Respir. Prot. 2017, $34,69-80$.

46. Kauranen, A. Finland's Emergency Supply Agency Head Quits over Face Mask Purchase. Available online: https://www.reuters. com/article/us-health-coronavirus-finland-facemasks-idUSKCN21S1NE (accessed on 7 August 2020). 
47. Aragaw, T.A. Surgical face masks as a potential source for microplastic pollution in the COVID-19 scenario. Mar. Pollut. Bull. 2020, 159, 111517. [CrossRef]

48. Fadare, O.O.; Okoffo, E.D. Covid-19 face masks: A potential source of microplastic fibers in the environment. Sci. Total Environ. 2020, 737, 140279. [CrossRef]

49. Armani, A.M.; Hurt, D.E.; Hwang, D.; McCarthy, M.C.; Scholtz, A. low-tech solutions for the COVID-19 supply chain crisis. Nat. Rev. Mater. 2020, 5, 403-406. [CrossRef]

50. Rajmohan, K.V.S.; Ramya, C.; Viswanathan, M.R.; Varjani, S. Plastic pollutants: Effective waste management for pollution control and abatement. Curr. Opin. Environ. Sci. Health. 2019, 12, 72-84. [CrossRef]

51. Yu, H.; Sun, X.; Solvang, W.D.; Zhao, X. Reverse logistics network design for effective management of medical waste in epidemic outbreaks: Insights from the Coronavirus Disease 2019 (COVID-19) outbreak in Wuhan (China). Int. J. Environ. Res. Public Health 2020, 17, 1770. [CrossRef]

52. Kulikowski, M. A Necessary Filter: Nonwovens Institute Steps Up to Combat COVID-19. Available online: https:/ /news.ncsu. edu/2020/04/a-necessary-filter/ (accessed on 3 August 2020).

53. University of Missouri Life-Saving Fabrics. Available online: https://news.missouri.edu/2020/life-saving-fabrics / (accessed on 3 August 2020).

54. Kalyaev, V.; Salimon, A.I.; Korsunsky, A.M. Fast mass-production of medical safety shields under COVID-19 quarantine: Optimizing the use of university fabrication facilities and volunteer labor. Int. J. Environ. Res. Public Health 2020, $17,3418$. [CrossRef] [PubMed]

55. Dai, T.; Bai, G.; Anderson, G.F. PPE supply chain needs data transparency and stress testing. J. Gen. Intern. Med. 2020, 35, 2748-2749. [CrossRef]

56. Buzacott, J.A.; Mandelbaum, M. Flexibility in manufacturing and services: Achievements, insights and challenges. Flex. Serv. Manuf. J. 2008, 20, 13-58. [CrossRef]

57. Lim, J. Apps show mask inventory for nearby locations in real time. Korea Herald, 13 March 2020.

58. Wan, K.M.; Ka-ki Ho, L.; Wong, N.W.M.; Chiu, A. World Development; Elsevier: Amsterdam, The Netherlands, 2020.

59. Joseph, G. Can Blockchain Save the Supply Chain from COVID-19? Available online: https://www.nasdaq.com/articles/canblockchain-save-the-supply-chain-from-covid-19-2020-04-21 (accessed on 3 October 2020).

60. Vecchi, V.; Cusumano, N.; Boyer, E.J. Medical supply acquisition in Italy and the United States in the era of COVID-19: The case for strategic procurement and public-private partnerships. Am. Rev. Public Adm. 2020, 50, 642-649. [CrossRef]

61. FDA Emergency Use Authorization I FDA. Available online: https:/ / www.fda.gov/emergency-preparedness-and-response/ mcm-legal-regulatory-and-policy-framework/emergency-use-authorization (accessed on 9 August 2020).

62. Katersky, A.; Doom, J. New York Man Accused of Hoarding COVID-19 Materials for Price Gouging-ABC News. Available online: https: / / abcnews.go.com/US/york-man-accused-hoarding-covid-19-materials-price/story?id=70333494 (accessed on 10 August 2020).

63. Matsakis, L. As Covid-19 spreads, Amazon tries to curb mask price gouging. Wired, 25 February 2020.

64. Nelson, S. Feds Distribute 200K N95 Masks Seized from Coronavirus Hoarder. Available online: https:/ / nypost.com/2020/04/ 02/feds-distribute-200k-n95-masks-seized-from-coronavirus-hoarder/ (accessed on 10 August 2020).

65. Nortes, S.; Battaglia, L.S.; Borowiec, S. Generation app: How do different generations feel about sharing personal data in order to tackle Covid-19? We ask people in South Korea, Spain and Italy. Index Censorsh. 2020, 49, 18-23. [CrossRef]

66. Orcutt, M. The Pandemic Has Messed up Global Supply Chains. Blockchains Could Help. I MIT Technology Review. Available online: https: / www.technologyreview.com/2020/04/07/998602/blockchains-covid19-supply-chain-wef/ (accessed on 3 October 2020).

67. Gopie, N. Blockchain's Role in COVID-19 Response and Recovery. Available online: https://www.ibm.com/blogs/blockchain/ 2020/04/blockchains-role-in-covid-19-response-and-recovery / (accessed on 3 October 2020).

68. Golan, M.S.; Jernegan, L.H.; Linkov, I. Trends and applications of resilience analytics in supply chain modeling: Systematic literature review in the context of the COVID-19 pandemic. Environ. Syst. Decis. 2020, 40, 222-243. [CrossRef]

69. Dolgui, A.; Ivanov, D.; Sokolov, B. Ripple effect in the supply chain: An analysis and recent literature. Int. J. Prod. Res. 2018, 56, 414-430. [CrossRef]

70. Silva, A.L.P.; Prata, J.C.; Walker, T.R.; Duarte, A.C.; Ouyang, W.; Barcelò, D.; Rocha-Santos, T. Increased plastic pollution due to COVID-19 pandemic: Challenges and recommendations. Chem. Eng. Sci. 2021, 405, 126683. [CrossRef] [PubMed] 